Please do not remove this page

RMIT

UNIVERSITY

\title{
The use of dynamic landscape metapopulation models for forest management: a case study of the red-backed salamander
}

Gordon, Ascelin; Wintle, Brendan; Bekessy, Sarah; Pearce, Jennie; Venier, Lisa; WIlson, Joab

https://researchrepository.rmit.edu.au/esploro/outputs/9921858664201341/filesAndLinks?institution=61RMIT_INST\&index=null

Gordon, A., Wintle, B., Bekessy, S., Pearce, J., Venier, L., \& WIlson, J. (2012). The use of dynamic landscape metapopulation models for forest management: a case study of the red-backed salamander. Canadian Journal of Forest Research, 42(6), 1091-1106. https://doi.org/10.1139/x2012-068 Document Version: Accepted Manuscript

Published Version: https://doi.org/10.1139/x2012-068

Repository homepage: https://researchrepository.rmit.edu.au

(C) 2012 NRC Research Press

Downloaded On 2023/04/27 00:18:32 +1000 
Thank you for downloading this document from the RMIT Research Repository.

The RMIT Research Repository is an open access database showcasing the research outputs of RMIT University researchers.

RMIT Research Repository: http://researchbank.rmit.edu.aul

\begin{abstract}
Citation:
Gordon, A, Wintle, B, Bekessy, S, Pearce, J, Venier, L and Wilson, J 2012, 'The use of dynamic landscape metapopulation models for forest management: a case study of the red-backed salamander', Canadian Journal of Forest Research, vol. 42, no. 6, pp. 1091-1106.
\end{abstract}

See this record in the RMIT Research Repository at:

https://researchbank.rmit.edu.au/view/rmit:16347

Version: Accepted Manuscript

Copyright Statement:

(C) The Authors

Link to Published Version:

http://dx.doi.org/10.1139/x2012-068 


\section{The use of Dynamic Landscape Metapopulation models for forest management: a case study of the red-backed salamander}

Ascelin Gordon $^{\mathrm{a}^{*}}$,Brendan A. Wintle ${ }^{\mathrm{b}}$, Sarah A. Bekessy ${ }^{\mathrm{a}, \mathrm{b}}$, Jennie L. Pearce ${ }^{\mathrm{c}, 1}$, Lisa A. Venier ${ }^{\mathrm{c}}$, Joab N. Wilson ${ }^{\mathrm{a}}$

aSchool of Global Studies, Social Science and Planning, RMIT University, GPO Box 2476V, Melbourne 3001, Victoria, Australia. ascelin.gordon@rmit.edu.au, sarah.bekessy@rmit.edu.au, jn.wilson@ballarat.edu.au

${ }^{\mathrm{b}}$ School of Botany, University of Melbourne, 3010, Victoria, Australia.

b.wintle@unimelb.edu.au

${ }^{\mathrm{c}}$ Great Lakes Forestry Centre, Canadian Forest Service, Natural Resources Canada, 1219 Queen St East, Sault Ste Marie, Ontario P6A 2E5, Canada. lisa.venier@nrcan-rncan.gc.ca

*Corresponding Author. Email: ascelin.gordon@rmit.edu.au, ph.: +613 99259930; fax: +613 99253088 Correspondence address: School of Global Studies, Social Science and Planning, RMIT University, GPO Box 2476V, Melbourne 3001, Victoria, Australia.

${ }^{1}$ Current address: Pearce and Associates Ecological Research, 1405 Third Line East, Sault Ste. Marie, ON, P6A 6J8, Canada. jlpearce@shaw.ca

Published as: Gordon A., Wintle B.A., Bekessy S.A., Pearce J., Venier L., Wilson J.N. (2012) The use of dynamic landscape metapopulation models for forest management: a case study of the red-backed salamander. Canadian Journal of Forest Research, 42: 1091-1106. doi: $10.1139 / \mathrm{x} 2012-068$ 


\begin{abstract}
Spatial models of population dynamics have been proposed as a useful method for predicting the impacts of environmental change on biodiversity. Here, we demonstrate advances in dynamic landscape metapopulation modelling (DLMP) and its use as a decision support tool for evaluating the impacts of forest management scenarios. This novel modelling framework incorporates both landscape and metapopulation model stochasticity and allows their relative contributions to model output variance to be characterised. It includes a detailed sensitivity analysis, allowing defensible uncertainty bounds and the prioritisation of future data gathering to reduce model uncertainties. We demonstrate this framework by modelling the landscapelevel impacts of eight forest management scenarios on the red-backed salamander (Plethodon cinereus) in the boreal forest of Ontario, Canada using the RAMAS Landscape package. The 100-year forest management scenarios ranged in intensity of timber harvesting and fire suppression. All scenarios including harvesting predicted decreases in salamander population size and the current style of forest management is predicted to produce a $9-17 \%$ decrease in expected minimum population size compared to scenarios without harvesting. This method is amenable to incorporating many forms of environmental change and allows a meaningful treatment of uncertainty.
\end{abstract}




\section{Introduction}

There has been an increasing emphasis on modelling species' response to environmental change with spatial habitat models (Thompson et al. 2003; Thomas et al. 2004). However, correlative models of species response to the availability and quality of habitat often do not explicitly consider environmental and demographic stochasticity, the spatial attributes of species' biology, and dynamic species-habitat occupancy probabilities (Davis et al. 1998; Dormann 2007; Fitzpatrick and Hargrove 2009). A move toward more mechanistic models for predicting the impacts of environmental change on biodiversity potentially circumvents some of the problems associated with using static correlative models of species habitat for this purpose (Akçakaya et al. 2004; Bekessy et al. 2008; Keith et al. 2008).

Dynamic landscape metapopulation (DLMP) models are an example of this approach and permit inferences about the impact of management and environmental change on individual species populations and provide a general framework to help inform future research priorities by identifying factors that most affect populations (Possingham et al. 1993; Wintle et al. 2005). DLMP models explicitly capture processes of extirpation and colonization and allow consideration of specific limitation to dispersal imposed by the spatial arrangement of habitat in the landscape and human modification of those spatial patterns (Wintle et al. 2005). They also provide the capacity to incorporate stochastic spatial processes such as fire and forest succession, enabling a more realistic picture of variability in long-term habitat availability.

A major challenge with using DLMP models (illustrated with this study) is that they tend to be highly parameterized and subject to severe uncertainties about environmental and population processes. Characterising these uncertainties is difficult due to the number of estimated parameters and the computation time required to run models and conduct detailed sensitivity analysis. However, if models are to be useful in decision-making, characterising uncertainty about key assumptions is crucial because minor deviations in assumptions can sometimes lead to qualitatively different management recommendations (Southwell et al. 2008). Failure to 
recognise and manage this form of uncertainty may result in unacknowledged biases in population model predictions (Burgman et al. 1993).

The use of DLMP software presents substantial challenges in testing the sensitivity of model outputs to the many assumptions made in the construction of the forest growth and succession models that are integral to DLMP. Here we extend the methods described by Wintle et al. (2005) and Chisholm and Wintle (2007) and demonstrate their potential use in management decision-making by assessing the long-term viability of the red-backed salamander (Plethodon cinereus) under a range of forest and fire management scenarios in northern Ontario, Canada. This case study is based on both field data and expert opinion and provides an opportunity to demonstrate comprehensive methods for understanding and incorporating the various uncertainties in our model. We demonstrate a detailed analysis of the sensitivity of the DLMP model to assumptions about vegetation, fire and population dynamics to provide insights into the most important sources of uncertainty in the DLMP model predictions. We also show how uncertainty relating to population and environmental stochasticity can be partitioned in the modelling process. This novel variance partitioning approach allowed us to optimize computational effort allocated between simulations of landscape and population dynamics.

\section{Materials and Methods}

We used the RAMAS Landscape software package (Akçakaya et al. 2003) to construct the redbacked salamander DLMP model. This package links the dynamic landscape model LANDIS 3.7 (Mladenoff and He 1999) and the metapopulation package RAMAS GIS 4 (Akçakaya and Root 2002a) using time steps at a 10-year temporal resolution. A schematic overview of the modelling process including the RAMS Landscape components is presented in Fig. 1. The process starts with the LANDIS software generating a series of maps representing forest change over time through successional processes and incorporating both deterministic (e.g., timber harvesting) and stochastic (e.g., fire) disturbances. The RAMAS GIS module then performs a 
patch recognition process on the LANDIS outputs and finally the RAMAS Metapop module runs metapopulation simulations. The various components in Fig. 1 are discussed in detail below. We ran the DLMP model using eight forest management scenarios, ranging in intensity from no timber harvesting and a natural fire regime to intensive forest harvesting with salvage logging after fire.

$<<$ Fig. $1>>$

\subsection{Study area}

The study area is located in the Central Plateau (Rowe 1972) of the Ontario boreal region and consists of an area of 170,000 hectares (Fig. 2). It is situated within the White River Sustainable Forest Licence (SFL), which has been actively managed for timber production for the past 35 years. The vegetation is dominated by jack pine (Pinus banksiana Lamb.), black spruce (Picea mariana Mill.), trembling aspen (Populus tremuloides Michx.), balsam fir (Abies balsamifera (L.) Mill.) and white birch (Betula papyrifera Marsh).

$<<$ Fig. $2>>$

\subsection{Habitat model}

The red-backed salamander (Plethodon cinereus) is a Plethodontid salamander found in moist microhabitats in wooded areas throughout North America. Plethodontid salamanders are lungless, respiring mostly through their skin, and thought to be strongly physiologically linked to microclimatic and successional gradients that influence forest floor microhabitat gradients (Welsh and Droege 2000). For these reasons and because of their longevity, small territory size, philopatry, sensitivity to disturbance and tendency to occur at high densities, Welsh and Droege (2000) recommend plethodontid salamanders as indicators of environmental change.

The red-backed salamander inhabits the organic soil and litter from deciduous-conifer forests. Higher densities of salamanders are found in mature forested habitats with scattered logs 
(Petranka 1998). Both quantitative abundance data and expert knowledge were available in the study area to guide the development of a habitat model describing the relationship between salamander abundance and variables such as forest composition, topography and microclimate (Pearce and Venier 2009). Details of the data and data collection methods and analysis are described in detail in Pearce and Venier (2009). In general, this data supported previous studies that showed higher numbers of salamanders were recorded in older forest (Harper and Guynn 1999; Ford et al. 2002), with higher moisture levels (deMaynadier and Hunter 1998) and that few salamanders were recorded in young re-growth less than 20 years old. The data also showed that salamanders tended to occur on sites with shallow soils and exposed rock, often in jack pine and black spruce mixtures.

The salamander abundance data in the study area (Pearce and Venier 2009) were used to explore salamander-habitat relationships using the classification tree technique (Hastie et al. 2001). Classification tree methods provided a simple technique to explore and characterise important statistical interactions between environmental variables that influence salamander abundance. We fitted classification trees in the statistical package R (version 2.0.1) using the package 'tree' (version 1.0-26) which chooses split-points to minimize deviance. The independent environmental variables that were offered to the classification tree model were 'cold' (mean temperature of the coldest period on a site), 'wetness' (relative moisture content of the site), 'elev' (elevation of a site) and 'age' (age of the dominant forest strata). These were used to generate trees that classify each location into one of three abundance categories: low ( 0 females/hectare), medium (2.5 females/hectare) and high (11.5 females/hectare). These categories were based on the observed mean density of salamanders in the study area (Pearce and Venier 2009) and assumed an even sex ratio (see Section 2.3). Because at the time of modelling there was no published salamander habitat model for our study region, we selected the candidate predictor variables (based on the literature cited above) as proxies to fundamental salamander habitat requirements. 
The best classification tree derived from the field survey data is represented in Fig. 3. A habitat suitability map was constructed by applying the classification tree algorithm to the raster layers representing the environmental variables in the classification tree. Predictions of the salamander abundance category were then used to determine the carrying capacity at each location (Fig. 1(c)). Tree species age and composition were determined using Forest Resource Inventory maps from 1970, which allowed us to determine tree species age and composition in the study area prior to timber harvesting (which started shortly after this date). This data was used for the initial conditions for LANDIS module and the dependence of the habitat suitability/carrying capacity on 'age' results in a dynamic suitability later that changes over time based on the LANDIS outputs (Fig. 1(b) -1(d)).

$<<$ Fig. $3>>$

\subsection{Population dynamics model}

Red-backed salamanders are entirely terrestrial and are considered common throughout their range in North America. Both male and female red-backed salamanders are territorial and aggressively defend high value microhabitats (Mathis 1989). Individuals can live for up to 10 years, with the average longevity of females estimated at 6-7 years (Leclair et al. 2008; J. Petranka personal communication).

Red-backed salamanders have a prolonged mating season (Petranka 1998) and an average clutch size ranging from five to thirteen eggs (Blanchard 1928). Approximately $80 \%$ of eggs will hatch into juveniles (J Petranka personal communication) and females breed biennially. Fecundity was estimated at 1.8 female juveniles produced per female every year (J Petranka personal communication).

A population model for the red-backed salamander was constructed using the Metapop module of RAMAS Landscape (Akçakaya and Root 2002b; Fig. 1(e)). The stage-structured population model comprised six stages, each with values for survival, fecundity and the probabilities of 
transition from each stage (Table 1). The model only included female stages, as the sex ratio is thought to be approximately even, the species is polygamous and there is no evidence for differences in vital rates between the sexes (Petranka 1998; J Petranka personal communication). In the absence of prior information about fluctuations in vital rates, the standard deviations in survival and fecundity were assumed to be $10 \%$ (J Petranka personal communication). Sensitivity analysis was used to test the influence of these assumptions on model predictions (see Appendix, Table A2 and Fig. 6).

Density dependence was modelled using the 'contest competition' setting in the Metapop module. This results in the average growth rate of the population being adjusted to follow the Beverton-Holt equation (Beverton and Holt 1957), which is used to represent strongly territorial species. We adjusted the model so that density dependence affected fecundity only, because reproduction is dependent on nest and territory availability (Friet 1995).

$$
<<\text { Table } 1>>
$$

\subsection{Linking habitat and population models}

The patch recognition algorithm within RAMAS GIS was used to determine discrete patches of habitat and the resultant patches are treated as discrete populations (Fig 1(c) and 1(d)). The algorithm requires an estimate of species' range movements and a threshold of habitat suitability below which cells would be considered unsuitable. Suitable habitat was defined as sites having a predicted habitat suitability classification of medium or high (see Section 2.2). Habitat patches separated by a 'neighbourhood' distance greater than 180 meters were considered discrete due to the short home range movements of the red-backed salamander (Waldick 1997; Petranka personal communication) and the initial number of individuals in each discrete patch was set to the patch's carrying capacity. The sensitivity of the model to the neighbourhood distance was studied with a subset of the data (Section A1, Appendix). 
There is considerable uncertainty in the dispersal range of the red-backed salamander with estimates ranging from 1.2 meters (Ousterhout and Liebgold 2010) to a maximum of 1.5 kilometres (Waldick 1997). In our model, the probability of dispersal between two patches was set to the best estimate for salamanders in study area (Petranka, personal communication). This comprised of a decreasing exponential dependence on the distance between the patches with maximum dispersal distance of 300 meters:

$$
M_{i j}=\left\{\begin{array}{ll}
0.7 \exp \left(-D_{i j} / 0.1\right) & 0<D_{i j}<0.3 \\
0 & D_{i j}>0.3
\end{array} .\right.
$$

Here, $M_{i j}$ is the probability of dispersal and $D_{i j}$ is the distance between the edges of patches $i$ and $j$ in kilometres. The sensitivity of the model to this parameterisation was determined by varying the dispersal parameters between a range bounded by the minimum case $\left(M_{i j}\right.$ set to zero for all distances) and the maximal case that had a shallower exponential decline and maximum dispersal distance of $6 \mathrm{~km}$ (see Appendix, Table A2).

\subsection{Forest dynamics model and management scenarios}

The LANDIS model was used to predict the future floristic composition and structure of the landscape under various management and natural disturbance scenarios (Fig. 1(a)). LANDIS produces a time series of maps that are used by the patch recognition algorithm in RAMAS GIS to define the metapopulation model in terms of patch structure, patch carrying capacities and other factors. The forest dynamics model is almost identical to that used in Wintle et al. (2005) and is briefly summarised here. The succession dynamics of the seven dominant tree species were modelled using life history parameters and historical inventory data. Two generic land types were identified with short and long fire-return intervals to define spatial variation in tree species establishment probabilities and forest composition. Based on the habitat requirements of the red-backed salamander, we defined several forest types (pure jack pine, pure black spruce 
forest, and a series of mixed forest types) for the LANDIS forest classification algorithm (Akçakaya et al. 2003).

Four silvicultural scenarios were simulated in LANDIS using various harvest size and salvage logging practices. They are described in detail in the Appendix (Table A1). Two fire regimes were applied to each of the four silvicultural scenarios, creating a total of eight scenarios. This consists of four scenarios with fire-return intervals and size distributions set to match to current esitmates and 'fire suppressed' versions of the same four scenarios (see Section A2 in the Appendeix for futher details). The fire suppressed scenarios assume that modern fire suppression methods are continued, resulting in an increase of both fire-return intervals and the distribution of fire sizes (Table A1, Appendix) and are distiguished from non-fire suppressed scenarios by a '/fire' at the end of the scenario name. The first scenario, titled No Harvest, was designated the reference scenario and has no timber harvesting and a natural fire regime. The second scenario is a fire-suppressed version of this titled No Harvest/Fire. For the remaining six scenarios, harvesting is spread over two rotations, the first during time steps 1 and 2 , the second during time steps 9 and 10. Scenarios 3 and 4 contain natural disturbance emulation harvesting with and without fire suppression and are titled Harvest/Fire and Harvest, respectively (see Table A1 and Section A2 in the Appendix for further details). The remaining four scenarios model more intensive silvicultural activity. In scenarios 5 and 6 (titled Intensive Harvest and Intensive Harvest/Fire) forestry workers remove coarse woody debris from areas that are logged and replant these areas with jack pine. Finally, scenarios 7 and 8 model the most intensive intervention where both harvested and burnt areas are replanted with jack pine. These scenarios, titled Intensive Harvest Salvage and Intensive Harvest Salvage/Fire, test the worstcase assumption that areas replanted with pure jack pine can never become suitable habitat (resulting in areas either burnt or harvested being excluded from becoming suitable habitat for the duration of the simulation). In the first 6 scenarios areas either burnt or logged can become 
suitable habitat after 20 years (as derived from the classification tree analysis, see Fig.2 and Section 2.2).

We also modelled the potential impacts of edge effects at the clearcut-forest interface following logging (scenarios 5-8; Fig. 1(b)). Current information suggests that within 25-35 meters of a clearcut edge, abundance may be reduced by approximately $20 \%$ (deMaynadier and Hunter 1998; deMaynadier and Hunter 1999). To incorporate the impacts of edge effects on surrounding non-silvicultural areas, we created a buffer zone of 100 meters around harvested or burnt patches. Within this region, the habitat suitability was reduced by $20 \%$ for one time-step of the LANDIS model (10 years). Buffers of smaller spatial and temporal sizes could not be modelled due to fixed 10 year time steps in LANDIS and the 100 meter resolution of the input maps.

\subsection{Running simulations and ranking management scenarios}

The DLMP model was used to evaluate and rank the eight forest management scenarios in terms of their impact on the landscape level abundance of the red-backed salamander (Fig. 1(f)). The impact was quantified with two variables, the expected minimum population size (EMP; McCarthy and Thompson 2001), and the end population (EP) size. The EP is the mean size of the population at the end of the metapopulation simulation and the EMP is calculated by recording the smallest population size that occurred over the 100-year simulation period for each iteration of the metapopulation model, and taking the average of these values. The EMP is useful in ranking scenarios as it provides a good indication of the propensity for population decline and is less sensitive to model assumptions (McCarthy and Thompson 2001).

\subsection{Stochasticity and sensitivity analysis}

Sensitivity analysis was conducted for 44 model parameters or settings (22 parameters in each of the LANDIS and metapopulation models) to determine if model predictions were sensitive to particular estimates, standard deviations of estimates or other assumptions of the model 
(Appendix, Table A2). Sensitivities were calculated as the relative percentage change in EMP resulting from a given change in a single parameter or model setting:

$$
S_{i}=\frac{\mathrm{P}_{i}-\mathrm{P}_{b}}{\mathrm{P}_{b}} \times 100
$$

where $S_{i}$ is the sensitivity of model $i, \mathrm{P}_{i}$ is the EMP of model $i$, and $\mathrm{P}_{b}$ is the EMP of the reference model (the No harvest scenario).

As population processes are generally thought to be subject to random environmental fluctuations, inclusion of stochastic variation in the metapopulation model parameters is recommended (McCarthy et al. 1994). Both demographic and environmental stochasticity were incorporated in the model using the stochasticity settings in RAMAS Metapop (Fig. 1(e)). Environmental stochasticity was assumed to be log-normally distributed and resulted in both the vital rates and carrying capacity varying with a standard deviation equal to $10 \%$ of their mean values. Spatial autocorrelation in demographic stochasticity is modelled explicitly in RAMAS Metapop through a correlation function that describes how correlation in the fluctuations of vital rates varies with distance between the patches:

$$
C_{i j}=0.5 * \exp \left(-D_{i j}^{1.1}\right)
$$

Here $C_{i j}$ is the correlation coefficient between patches $i$ and $j$ and $D_{i j}$ is the distance between the centres of patches $i$ and $j$ in kilometres. Due to a lack of information for specifying the demographic and environmental stochasticity and the extent to which it is autocorrelated, an assessment of the sensitivity of the model to alternative assumptions was carried out (see Appendix, parameters $c 1$ and $c 2$, Table A2).

While RAMAS Landscape was designed to deal with demographic and environmental stochasticity, it is also important to consider the contribution from landscape stochasticity. 
Chisholm and Wintle (2007), suggest an algorithm for minimising the total variance in model outcomes by balancing the variability from the landscape and metapopulation models. The algorithm is implemented within a software package called Repeater, designed to work with RAMAS Landscape (Chisholm and Wintle 2007). Repeater allows the trade-off between generating multiple landscapes using LANDIS (computationally expensive) and performing multiple metapopulation runs on each landscape (computationally cheap) to be optimised. In this study, we used the Repeater package to automate the process of running the metapopulation model over multiple landscape realisations (Fig. 1(g)). It enables the total variance in measures such as the EMP to be separated into landscape and metapopulation components and is able to iteratively calculate the optimal number of metapopulation runs per landscape to minimise total variance in the EMP (Chisholm and Wintle 2007). Our approach enables coherent aggregation of variance components across metapopulation and landscape model predictions, providing a more realistic expression of total predictive uncertainty than can usually be achieved under the standard implementation of DLMP models (e.g. Akçakaya et al. 2004; Wintle et al. 2005).

\section{Results}

\subsection{Habitat availability}

As carrying capacity $(\mathrm{K})$ is linearly related to the amount and quality of habitat, it can be used to assess the impact of each scenario on the availability of habitat. Fig. 4 shows how the total $\mathrm{K}$ for the study region changes with time for each of the scenarios. The mean $\mathrm{K}$ for the No harvest scenario is shown overlaid as a dashed line for reference. Table 2 presents the numerical values for the total $\mathrm{K}$ integrated over the 100 years of simulation for each of the scenarios.

Variation in $\mathrm{K}$ was greater in all scenarios with fire suppression, as fires occur less often but burn a larger area with greater intensity. The impact of natural disturbance emulation harvesting is shown in the Harvest scenario where there are visible drops in $\mathrm{K}$ occurring during the first and the second harvest rotations (depicted with the vertical grey lines in Fig. 4). The 
management impacts remain relatively constant for the other harvesting scenarios with the exception of the Intensive Harvest Salvage scenarios. In these scenarios salvage logging occurs in burnt areas, which are replanted with jack pine and excluded from becoming suitable habitat. This results in a gradual decline in $\mathrm{K}$ as more areas are excluded from becoming habitat. In all scenarios with management impacts, the effect of landscape stochasticity was generally smaller than the impact of harvesting as measured by the reduction in $\mathrm{K}$ from the No Harvest scenario during the harvest rotations.

$<<$ Fig. $4>>$

\subsection{Population size}

Fig. 5 presents the population trajectories for each scenario, showing the mean, maximum and minimum population size. In all scenarios the population trajectories start with approximately 110,000 individuals. Scenarios 1 and 2 remain approximately flat for the duration of the simulation, reflecting the stable $\mathrm{K}$ without management impacts. As with $\mathrm{K}$, the variance in population trajectories tends to be greater in the fire suppressed scenarios.

All scenarios that included harvesting predicted decreases in population size (Fig. 5; scenarios 3 - 8). Although no scenarios indicated a decline to extinction, the scenarios differed in the relative risk of decline to various population sizes. This can be seen in Table 2 and by comparing the trajectories resulting from each of the silvicultural management scenarios to the trajectory of the No Harvest scenario (overlaid as a dashed line on scenarios $2-8$, Fig. 5). Based on the sensitivities shown in Table 2, the Harvest/Fire and Intensive Harvest/Fire scenarios resulted in a predicted 9-17\% decrease in EMP for the red-backed salamander over the next 100 years compared to scenarios with no harvesting. These scenarios most closely resemble the current style of forest management in the study area (scenarios 4 and 6, Fig. 5). In the four harvesting scenarios without salvage logging, both harvested and burnt areas are allowed to regenerate and can become suitable habitat after 20 years. Reductions in the mean 
population size are visible during the years harvesting occurs and subsequently the mean population size gradually recovers to the levels in the No Harvest scenario within approximately 20 years (scenarios $3-6$, Fig. 5). The worst-case situation is modelled in the Intensive Harvest Salvage scenarios. This results in more significant decreases in population size relative to the Intensive Harvest scenarios, as habitat is steadily lost over time due to burnt areas being replanted with jack pine (scenarios 7 and 8, Fig. 5). The Intensive Harvest scenarios also include the impact of a $100 \mathrm{~m}$ edge effect that reduced $\mathrm{K}$ by $20 \%$ in the affected area (see Section 2.5).

$$
<<\text { Table } 2>><<\text { Fig. } 5>>
$$

Table 2 shows EMP and EP values for each scenario along with their sensitivities relative to the No Harvest scenario. The EMP for the No Harvest scenario had a value of $89660 \pm 582$ individuals while the highest impact occurred in Intensive Harvest Salvage/Fire scenario, which resulted in the EMP decreasing by 28 percent relative to the No Harvest scenario. The other silvicultural management scenarios fell between these two extremes. It is important to note that the given range in the EMP corresponds to the standard error of the mean of the minimum population sizes across multiple simulations, making it a constrained statistic. A more intuitive impression of the uncertainty about population projections can be observed in the population trajectory plots (Fig. 5), where the absolute range of simulated values is around $50000-100$ 000 individuals depending on the scenario being modelled. The EMP was more sensitive to increasing disturbance than the EP but both variables show a similar trend in decreasing with increasing intensity of management.

\subsection{Sensitivity analysis}

The results of the sensitivity analysis are presented in Fig. 6. Sensitivities were determined by varying parameters within their estimated range (or by $20 \%$ when no estimates of variability were available) or by changing discrete settings in the software. Table A2 in the Appendix contains a description of the changes in the model that correspond to the alphanumeric codes 
used in Fig. 6. The DLMP model was less sensitive to variations in the LANDIS model than the RAMAS GIS and Metapop components, with EMP sensitivities falling within 10\% of the reference model for all model variations tested. The most sensitive elements were those controlling seed dispersal and seeding distance $(s 2, d 2)$, longevity $(l 4)$ and fire suppression $(f 1$; Fig. 6; Appendix, Table A2). The output of the DLMP model was significantly more sensitive to the RAMAS GIS/Metapop parameters, with the most sensitive parameters being the determination of $\mathrm{K}(k 1, k 2)$ and the assumptions regarding the effect of density dependence on vital rates $(d d 1, d d 2)$. Varying $\mathrm{K}$ involved changing the number of females per hectare for each of the habitat suitability categories. A $20 \%$ increase or decrease in K produced similar variation in both EMP and EP values. In constructing the red-backed salamander metapopulation model we assumed that density dependence affected fecundity only. The worst case assumption that density dependence affects both fecundity and survival ( $d d 2)$ resulted in a $21 \%$ decrease in EMP values while assuming that density dependence affects survival $(d d l)$ produces a decrease in EMP value of $17 \%$. Changing the value of $\mathrm{R}_{\max }(r 1, r 2$; the rate at which the population increases when it is small enough to have no density dependence) also affected model output, but to a lesser extent. A $20 \%$ increase or decrease in $\mathrm{R}_{\max }$ produced $+4 \%$ or $-8 \%$ changes in the EMP values, respectively. The sensitivity of the neighbourhood distance (ND) was also investigated with a subset of the data consisting of an area of approximately one quarter of the total area of the original data. Reducing the ND by more than $20 \%$ resulted in sensitivities for EMP of around 10\% (see Section A1 in the Appendix for further details).

$<<$ Fig. $6>>$

\subsection{Environmental and demographic stochasticity}

Table 3 summarises information produced by the Repeater software relating to the relative sizes of the landscape and metapopulation stochasticity. The landscape stochasticity contribution to the total variance in the EMP was generally found to be less than the contribution from the metapopulation stochasticity, except in scenarios 7 and 8 (Table 3). The ratio of landscape to 
metapopulation EMP variance ranged between 0.44 (the No Harvest scenario) and 21.2 (the Intensive Harvest Salvage/Fire scenario) with a median value over all scenarios of 0.92 (Table 3). The time for a single landscape realisation was approximately 150 times greater then the time for a single realisation of the metapopulation model. Factoring in this difference, the Repeater software usually stabilised to running between 3-30 metapopulation model repetitions per landscape realisation (Table 3).

$$
<<\text { Table } 3>>
$$

\section{Discussion}

This paper presents a DLMP modelling framework and demonstrates this method through a case study that evaluates the impacts of forest management scenarios on the red-backed salamander. The scenario analysis we present illustrates a sound framework within which to analyse forest management impacts on biodiversity, though we would hope that significant refinements to our model would be undertaken before it was used to underpin management decision-making or forest policy. A feature of the analysis presented here is that we use several methods to explore the impacts of the uncertainties present in our data. These include i) the uncertainty arising from imperfect knowledge about the state of nature (parameter and model uncertainty), through a sensitivity analysis, and ii) the uncertainties resulting from the inherent randomness, in the form of environmental and demographic stochasticity, and interactions between environmental and population processes, all of which were handled with the Repeater package. This treatment of the different sources of uncertainty permitted robust comparisons of different management scenarios with justifiable bounds on quantitative measures of impact (such as the EMP or EP).

\subsection{Parameter and model uncertainty}

We demonstrated the importance of a detailed sensitivity assessment for models with large numbers of parameters. In doing this, we varied 44 parameters in both the LANDIS and metapopulation components of the red-backed salamander DLMP model were assessed. It was encouraging to see that the LANDIS model was not particularly sensitive to variation, with 
EMP sensitivities falling within $10 \%$ of the reference model for all model variations tested (Fig. 6(a)). There were four parameters in the metapopulation model that appeared important, with uncertainty in these parameters having a similar impact to the silvicultural scenarios modelled (Fig. 6(b)). These parameters related to specifying $\mathrm{K}(k 1, k 2)$ and assumptions about the density dependence $(d d 1, d d 2)$.

The parameters used to determine $\mathrm{K}$ were based on actual survey information for the study area (Pearce and Venier 2009), and a number of assumptions were made in their estimation. These included perfect detectability, although the detectability probability in reality may be low, it has been shown to be greater than $15 \%$ in other areas (Otto and Roloff 2011). Thus in our model, $\mathrm{K}$ represents the lower limit of the expected realistic parameter estimate. Although the sensitivity analysis revealed that increasing $\mathrm{K}$ for occupied habitat would change model predictions about the absolute population size, it did not alter the relative rankings of the scenarios, as changes in $\mathrm{K}$ increased the salamander populations across all scenarios. Thus improving estimates of $\mathrm{K}$ would help increase the accuracy of results for individual scenarios and could be achieved within an adaptive management framework, but this may not provide additional discrimination between scenarios. When faced the decisions around different management options, the ranking or discrimination between scenarios can be a more useful measure, as this information can be directly used in the decision-making procedure. Rankings can also be more robust to uncertainty as some systematic errors (such as the determination of $\mathrm{K}$ ) may be mostly cancelled out when taking the difference between scenarios.

\subsection{Environmental and demographic stochasticity}

Use of the Repeater package enabled the partitioning of the contributions of the population and landscape models to the variance in persistence measures (such as EMP). This revealed that the contribution of landscape stochasticity to the red-backed salamander was lower than other species that have been modelled in the same area such as the brown creeper (Certhia americana; Wintle et al. 2005). The relative insensitivity of the salamander to landscape level 
variation is not completely unexpected given its smaller range size and relatively rapid recovery of habitat from fire compared with the brown creeper. As shown in Fig. 3, the maximum habitat suitability for the red-backed salamander could be reached 20 years after fire, while this took over 100 years for the brown creeper (Wintle et al. 2005). There was also an increased contribution of landscape variation to EMP variance in the Intensive Harvest Salvage scenarios in the red-backed salamander model. Interestingly, in these scenarios landscape variation was significantly greater then the metapopulation variation (Table 3). This increase results from the landscape 'storing' the fire history through burnt areas being excluded from becoming habitat in these scenarios. In this situation no steady state in $\mathrm{K}$ can be reached between fire and regeneration. These results demonstrate the importance of considering the contribution of both demographic and landscape stochasticity and that it is not always clear a priori which impact will be more important. Undertaking multiple landscape realisations is not currently practical in RAMAS Landscape without the use of the external Repeater package, as RAMAS Landscape is designed to be used with a single landscape realisation.

\subsection{Impact of different scenarios}

The red-backed salamander model showed that the reference No Harvest and No Harvest/Fire scenarios had a relatively stable total $\mathrm{K}$ over the 100 years of simulation. The severity of the impact of harvesting was driven by assumptions regarding recovery of habitat suitability after harvesting, the inclusion of salvage logging and the effects of fire suppression methods. For example, comparing the Intensive Harvest Salvage scenarios to those with less intensive harvesting revealed declines in EMP that were 2-3 times greater in the fire suppressed scenarios and approximately 4 times greater in the non-fire suppressed scenarios. The inclusion of an edge effect (the Intensive Harvest and Intensive Harvest Salvage scenarios) produced a negligible impact on the total $\mathrm{K}$ and on the salamander population trajectories (Fig. 5). Increasing the severity of the edge effect (in terms of its impact on $\mathrm{K}$ and the distance over which it operates) 
produced significant impacts on the population trajectories, but there is currently no evidence for larger edge effects on temperate forest salamanders (deMaynadier and Hunter 1999).

The use of multiple realisations of both the landscape model and population model allows the impact of forest management to be quantified relative to the impact of stochasticity. Averaging over landscape and metapopulation model realisations allows a more realistic estimate of the variance of parameters used to quantify the impacts of different forest management scenarios.

The use of Repeater also enables implementation of non-standard processes in the population model (Fig. 1(b)). Using Repeater we were able to explicitly model the spatial population implications of edge effects on the long-term viability of the red-backed salamander. The flexibility of Repeater makes it amenable to incorporating many other forms of environmental change within the RAMAS Landscape framework including additional spatially explicit impacts including urbanization, climate change or bio-invasion.

\section{Conclusions}

We demonstrate advances in dynamic landscape metapopulation modelling (DLMP) as a decision support tool for evaluating the impacts of different forest management scenarios. This novel modelling framework incorporates multiple sources of uncertainty and provides a sound basis for decision theoretic approaches to in choosing among management options. In many situations, forest management planning must be conducted in the absence of suitable data on a number of relevant species. This approach allows initial predictions with defensible uncertainty bounds on the probable outcomes of management options. It also highlights the model components producing the greatest uncertainties, allowing forest managers to allocate resources to reduce this uncertainty through research or monitoring and thus can be built into an adaptive management framework.

\section{Acknowledgements}


This project was supported by The Ontario Living Legacy Trust, Project No. 07-029 and the Canadian Forest Service. A.G. was supported by ARC LP 0454979 and ARC LP 0882780. B.W. was supported by a Land and Water Australia Travelling Fellowship and ARC LP 347473. Mike Flannigan, Tim Lynham and Erin Bosch (Canadian Forest Service) provided data for estimating fire parameters and Jim Bogart (University of Guelph) and James Petranka (University of North Carolina) provided advice on the population model parameters. Kevin Lawrence, Teri Bonnell and Gillian Eccles provided GIS and technical support. Resit Akçakaya (Applied Biomathematics), David Mladenoff (University of Wisconsin), Jane Elith, Mick McCarthy, Prema Lucas and Mark Burgman (University of Melbourne) provided technical advice on modelling and comments on the manuscript. 


\section{References}

Akçakaya, H.R., and Root, W. 2002a. RAMAS GIS: Linking Spatial Data with Population Viability Analysis (version 4.0). Applied Biomathematics. Setauket, New York.

Akçakaya, H.R., and Root, W. 2002b. RAMAS Metapop: Viability Analysis for Stagestructured Metapopulations (version 4.0). Applied Biomathematics. Setauket, New York.

Akçakaya, H.R., Mladenoff, D.L., and He, H.S., 2003. RAMAS Landscape: integrating metapopulation viability with LANDIS forest dynamics model. User manual for version 1.0. Applied Biomathematics. Setauket, New York.

Akçakaya H.R., Radeloff, V.C., Mlandenoff D.J., and He H.S. 2004. Integrating landscape and metapopulation modeling approaches: Viability of the sharp-tailed grouse in a dynamic landscape. Conserv. Biol. 18: 526-537.

Bekessy, S.A., Wintle, B.A., Gordon, A., Chisholm, R.A., Venier, L., and Pearce, J. 2008. Dynamic Landscape Meta-population Models and Sustainable Forest Management. In Models for planning wildlife conservation in large landscapes. Edited by J.J. Millspaugh and F.R. Thompson. Elsevier Science, The Netherlands. pp 473-499.

Beverton, R.J.H., and Holt, S.J., 1957. On the Dynamics of Exploited Fish Populations. Fishery Investigations Series 2, Vol 19. UK Ministry of Agriculture and Fisheries, London.

Blanchard, F.N., 1928. Topics from the life history and habits of the red-backed salamander in southern Michigan. The Am. Nat. 62: 156-164.

Burgman, M.A., Ferson, S., and Akçakaya, H.R. 1993. Risk assessment in conservation biology. Chapman and Hall, London.

Chisholm, R.A., and Wintle, B.A. 2007. Landscape stochasticity in population viability analysis. Ecol. Appl. 17: 317-322.

Davis, A.J., Jenkinson, L.S., Lawton, J.H., Shorrocks, B., and Wood, S. 1998. Making mistakes when predicting shifts in species range in response to global warming. Nature. 391: 783786.

deMaynadier, P.G., and Hunter, M.L. 1998. Effects of Silvicultural Edges on the Distribution and Abundance of Amphibians in Maine. Conserv. Biol. 12: 340-352.

deMaynadier, P.G., and Hunter, M.L. 1999. Forest canopy closure and juvenile emigration by pool-breeding amphibians in Maine. J.Wildlife Manage. 63: 441-450.

Dormann, C.F. 2007. Promising the future? Global change projections of species distributions. Basic Appl. Ecol. 8: 387-397. 
Fitzpatrick, M.C., and Hargrove, W.W. 2009. The projection of species distribution models and the problem of non-analog climate. Biodivers. Conserv. 18: 2255-2261.

Ford, W.M., Chapman, B.R., Menzel, M.A., and Odom, R.H. 2002. Stand age and habitat influences on salamanders in Appalachian cove hardwood forests. Forest Ecol. Manag, 155: $131-142$.

Friet, S.C. 1995. Plethodon cinerus (eastern red-backed salamander); Nest behaviour. Herpetol. Rev. 26: 198-199.

Harper, C.A., and Guynn, D.C. 1999. Factors affecting salamander density and distribution within four forest types in the southern Appalachian Mountains. Forest Ecol. Manag. 114: $245-252$

Hastie, T., Tibshirani, R. and Friedman, J.H. 2001. The elements of statistical learning: data mining, inference, and prediction. Springer-Verlag, New York.

Keith, D.A., Akçakaya, H.R., Thuiller, W., Midgley, G.F. Pearson, R.G., Phillips, S.J., Regan, H.M., Araújo, M.B., and Rebelo, T.G. 2008. Predicting extinction risks under climate change: coupling stochastic population models with dynamic bioclimatic habitat models. Biol. Let. 4: 560-563.

Mathis, A. 1989. Do seasonal spatial patterns in terrestrial salamander reflect reproductive behavior or territoriality? Copeia. 3: 788-791.

McCarthy, M.A., and Thompson, C. 2001. Expected minimum population size as a measure of threat. Anim. Conserv. 4: 351-355.

McCarthy, M.A., Franklin, D.C., and Burgman, M.A. 1994. The importance of demographic uncertainty - an example from the Helmeted Honeyeater Lichenostomus melanops cassidix. Biol. Conserv. 67: 135-42.

Mladenoff, D.J., and He, H.S. 1999. Design and behavior of LANDIS, an object-oriented model of forest landscape disturbance and succession. In Advances in spatial modeling of forest landscape change: approaches and applications. Edited by D.J. Mladenoff and W.L. Baker. Cambridge University Press, Cambridge, UK.

Otto, C.R., and Roloff, G.J. 2011. Using multiple methods to assess detection probabilities of forest-floor wildlife. J. Wildl. Manage. 75: 423-431.

Ousterhout, B.H., and Liebgold, E.B. 2010. Dispersal Versus Site Tenacity of Adult and Juvenile Red-Backed Salamanders (Plethodon cinereus). Herpetologica. 66: 269-275.

Pearce, J., and Venier, L. 2009. Are salamanders good bioindicators of sustainable forest management in boreal forests? Can. J. Forest Res. 39: 169-179. 
Petranka, J.W. 1998. Salamanders of the United States and Canada. Smithsonian Institution Press, Washington and London.

Pfingsten, R.A. 1989. Salamanders of Ohio. Ohio Biological Survey Bulletin, New Series. 7, 269-275.

Possingham, H.P., Lindenmayer, D.B., and Norton, T.W. 1993. A framework for the improved management of threatened species based on population viability analysis. Pac. Conserv. Biol. 1: 39-45.

Rowe, J.S. 1972. Forest Regions of Canada. Dept of the Environment, Canadian Forestry Service, Ottawa.

Southwell, D.M., Lechner, A., Coates, T., and Wintle, B.A. 2008. The sensitivity of population viability analysis to uncertainty about habitat requirements: Implications for the management of the endangered Southern Brown Bandicoot. Conserv. Biol. 22: 045-1054.

Thomas, C.D., Cameron, A., Green, R.E., Bakkenes, M., Beaumont, L.J., Collingham, Y.C., Erasmus, B.F.N., de Siqueira, M.F., Grainger, A., Hannah, L., Hughes, L., Huntley, B., van Jaarsveld, A.S., Midgley, G.F., Miles, L., Ortega-Huerta, M.A., Peterson, A.T., Phillips, O.L., and Williams, S.E. 2004. Extinction risk from climate change. Nature. 427: $145-148$.

Thompson, I.D., Baker J.A., and Ter-Mikaelian, M. 2003. A review of the long-term effects of post-harvest silviculture on vertebrate wildlife, and predictive models, with an emphasis on boreal forests in Ontario. Can. Forest Ecol. Mange, 177: 441-469.

Vogt, R.C. 1981. Natural History of Amphibians and Reptiles of Wisconsin. Milwaukee Public Museum, Milwaukee, Wisconsin.

Waldick, R. 1997. Effects of forestry practices on amphibian populations in eastern north America. Herpetol. Conserv. 1: 191-205.

Welsh, H.H. and Droege, S., 2001. A case for using Plethodontid salamanders for monitoring biodiversity and ecosystem integrity of North American forests. Conserv. Biol. 15: 558569.

Wintle, B.A., Bekessy, S.A., Venier, L.A., Pearce, J.L., and Chisholm, R.A. 2005. Utility of dynamic-landscape metapopulation models for sustainable forest management. Conserv. Biol. 19: 1930-43. 


\section{Tables}

Table 1. The survival, fecundity and transition rates used in each stage of the red-backed salamander population model. The Transition column describes how salamanders move between the stages in the model and the associated probabilities of each transition. The Survival and Fecundity column gives the proportion of salamanders that survive a given stage and the amount of offspring that can be produced. Parameters for which no source is given were derived from expert opinion (J. Petranka and J. Bogart).

\begin{tabular}{|c|c|c|c|}
\hline Stage & Description & Survival and Fecundity & Transition \\
\hline $\begin{array}{l}\text { Juvenile } \\
1\end{array}$ & $\begin{array}{l}<12 \text { months } \\
\text { (non-breeding) }\end{array}$ & $60 \%$ survival, $10 \%$ standard deviation & $\begin{array}{l}\text { Survivors move to } \\
\text { juvenile } 2\end{array}$ \\
\hline $\begin{array}{l}\text { Juvenile } \\
2\end{array}$ & $\begin{array}{l}12 \text { months }-2 \text { years } \\
\text { (non-breeding) }\end{array}$ & $60 \%$ survival, $10 \%$ standard deviation & $\begin{array}{l}\text { Survivors move to } \\
\text { juvenile } 3\end{array}$ \\
\hline $\begin{array}{l}\text { Juvenile } \\
3\end{array}$ & $\begin{array}{l}2 \text { years }-\sim 3.5 \text { years } \\
\text { (non-breeding) }\end{array}$ & $60 \%$ survival, $10 \%$ standard deviation & $\begin{array}{l}10 \% \text { remain in } \\
\text { juvenile } 3,50 \% \text { move to } \\
\text { adult } 1 \text { stage }\end{array}$ \\
\hline Adult 1 & $\begin{array}{l}\text { Breed once every } 2 \text { years } \\
\text { (Pfingsten 1989, Vogt } \\
\text { 1981) }\end{array}$ & $\begin{array}{l}65 \% \text { survival, } 10 \% \text { standard deviation } \\
1.8 \text { female juveniles produced per } \\
\text { female adult, } 10 \% \text { standard deviation }\end{array}$ & $\begin{array}{l}25 \% \text { remain in adult } 1, \\
40 \% \text { move to adult } 2 \\
\text { stage }\end{array}$ \\
\hline Adult 2 & $\begin{array}{l}\text { Sexually mature, breed } \\
\text { once every } 2 \text { years }\end{array}$ & $\begin{array}{l}75 \% \text { survival }, 10 \% \text { standard deviation } \\
1.8 \text { female juveniles produced per } \\
\text { female adult } 2,10 \% \text { standard deviation }\end{array}$ & $\begin{array}{l}25 \% \text { remain in adult } 2, \\
50 \% \text { move to adult } 3 \\
\text { stage }\end{array}$ \\
\hline Adult 3 & $\begin{array}{l}\text { Sexually mature, breed } \\
\text { once every } 2 \text { years }\end{array}$ & $\begin{array}{l}30 \% \text { survival, } 10 \% \text { standard deviation. } \\
\text { Average longevity: } 6-7 \text { years with a } \\
\text { maximum of } 10 \text { years } \\
1.8 \text { female juveniles produced per } \\
\text { female adult } 2,10 \% \text { standard deviation }\end{array}$ & \\
\hline
\end{tabular}


Table 2. Comparison of the eight forest management scenarios for the red-backed salamander DLMP model. Summed K is a measure of the total carrying capacity of the landscape, summed over the 100 years of simulation with the sensitivity or percent decline (equation 2) relative to Scenario 1 shown within square parentheses. EMP is the expected minimum population size, EP is the mean population size at the end of the simulation. The sensitivities for the EMP values are shown in a separate column with along with the standard error (SE) in these values.

\begin{tabular}{|c|c|c|c|c|c|c|c|}
\hline \multirow[b]{2}{*}{ Scenario } & \multirow{2}{*}{$\begin{array}{l}\text { Summed K } \\
\quad \times 10^{3} \\
\text { (individuals) } \\
\text { [sensitivity] }\end{array}$} & \multicolumn{2}{|c|}{ EMP (individuals) } & \multicolumn{2}{|c|}{ EP (individuals) } & \multicolumn{2}{|c|}{ Sensitivity (EMP) } \\
\hline & & mean & SE(mean) & mean & SE(mean) & $\mathbf{S}$ & SE(S) \\
\hline 1. No Harvest & $11700[-]$ & 89660 & 582 & 102406 & 1019 & - & - \\
\hline 2. No Harvest/Fire & $11528[-1.47]$ & 84412 & 1003 & 95822 & 2261 & -5.85 & 1.27 \\
\hline 3. Harvest & $11178[-4.46]$ & 83381 & 608 & 85587 & 662 & -7.00 & 0.91 \\
\hline 4. Harvest/Fire & $11156[-4.65]$ & 81368 & 1497 & 86097 & 1268 & -9.25 & 1.77 \\
\hline 5. Intensive Harvest & $11200[-4.27]$ & 84403 & 761 & 87240 & 1063 & -5.86 & 1.05 \\
\hline 6. Intensive Harvest/Fire & $11462[-2.03]$ & 74389 & 1113 & 84961 & 2231 & -17.03 & 1.35 \\
\hline 7. Intensive Harvest & $9022[-22.89]$ & 65445 & 1255 & 67117 & 1381 & -27.01 & 1.48 \\
\hline Salvage & & & & & & & \\
\hline 8. Intensive Harvest & $9077[-22.41]$ & 64191 & 2725 & 69064 & 3734 & -28.41 & 3.07 \\
\hline Salvage/Fire & & & & & & & \\
\hline
\end{tabular}


Table 3. Summary information used by the Repeater package to determine the optimal number of metapopulation runs per landscape realisation. $T_{l} / T_{m}$ is the ratio of running times for a single landscape realisation to a single metapopulation model run; $R_{m} / R_{l}$ is final number of metapopulation model repetitions per landscape realisation after 90 minutes of running; $\operatorname{Var}($ landscape) / Var(metapopulation) is the ratio of landscape EMP variance to metapopulation EMP variance.

\begin{tabular}{lccc}
\hline Scenario & $\boldsymbol{T}_{\boldsymbol{l}} / \boldsymbol{T}_{\boldsymbol{m}}$ & $\boldsymbol{R}_{\boldsymbol{m}} / \boldsymbol{R}_{\boldsymbol{l}}$ & $\begin{array}{c}\text { Var(Iandscape) } \\
\text { Var(metapopulation) }\end{array}$ \\
\hline 1 & 139.2 & 17 & 0.44 \\
2 & 145.4 & 13 & 0.92 \\
3 & 123.7 & 15 & 0.54 \\
4 & 118.5 & 7 & 2.59 \\
5 & 121.0 & 11 & 0.92 \\
6 & 427.7 & 30 & 0.48 \\
7 & 107.3 & 5 & 5.21 \\
8 & 168.7 & 3 & 21.22 \\
mean & $\mathbf{1 6 8 . 9}$ & $\mathbf{1 2}$ & $\mathbf{4 . 0 0}$ \\
median & $\mathbf{1 3 1 . 4}$ & $\mathbf{1 2}$ & $\mathbf{0 . 9 2}$ \\
SE & $\mathbf{1 0 6 . 3}$ & $\mathbf{9}$ & $\mathbf{7 . 1 3}$ \\
\hline
\end{tabular}




\section{Figures}

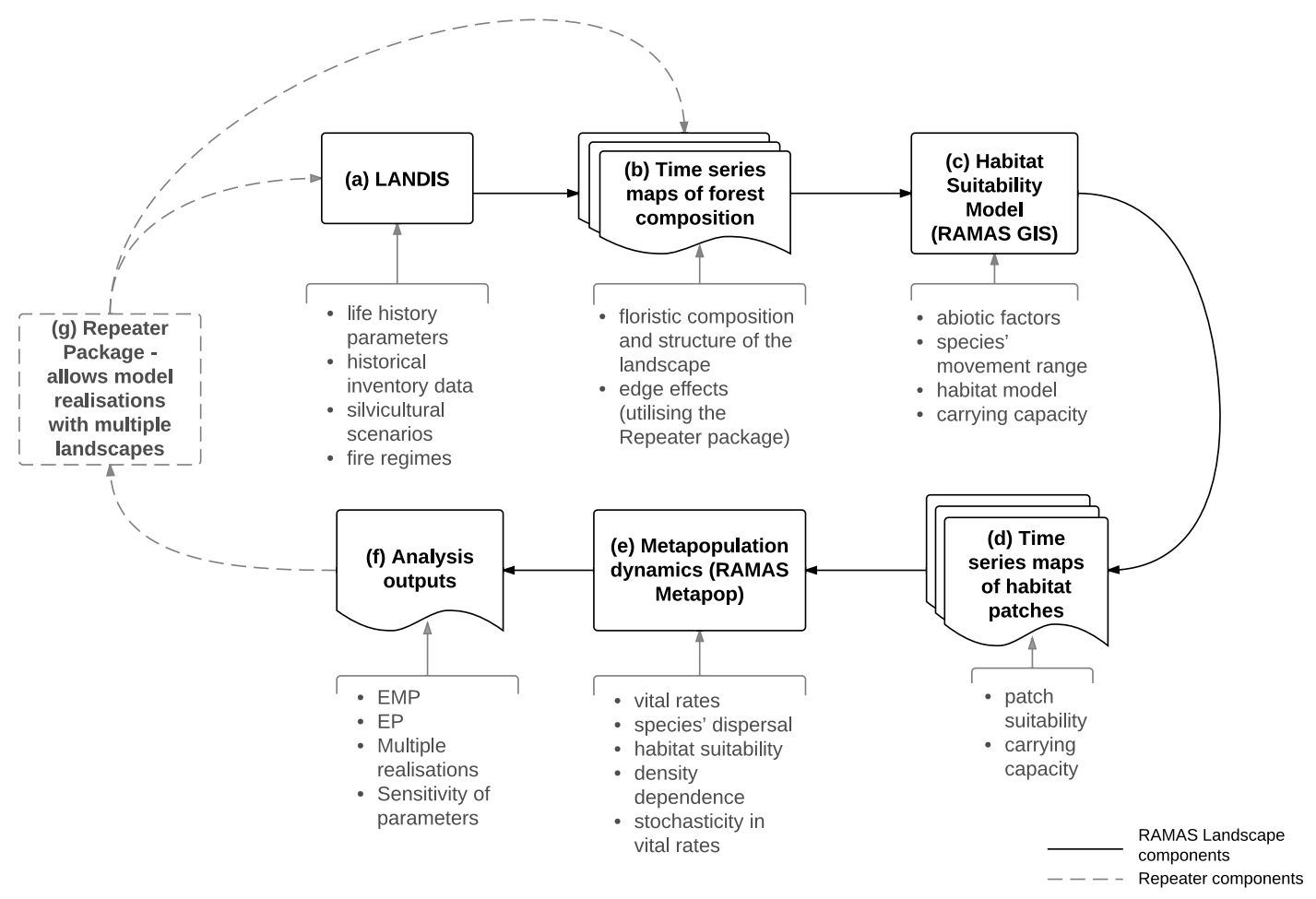

Fig. 1. Schematic flow chart representation of the modelling process used in the red-backed

salamander DLMP model. Components (a) - (f) comprise the RAMAS Landscape package. The notes list some of the important features associated of each component of the modelling process. 


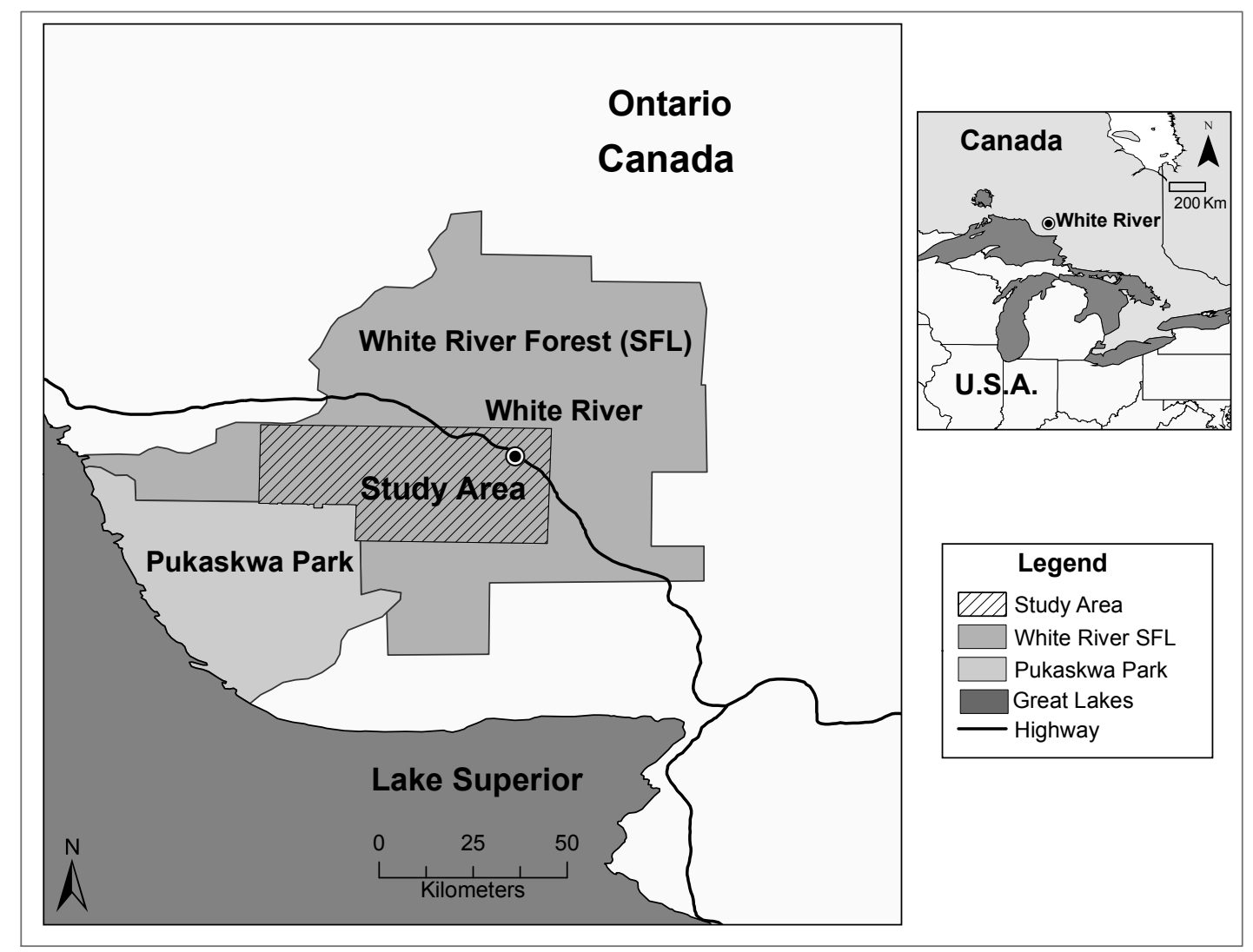

Fig. 2. Map of the study area within the White River Sustainable Forest Licence (SFL), in north central Ontario, Canada. 


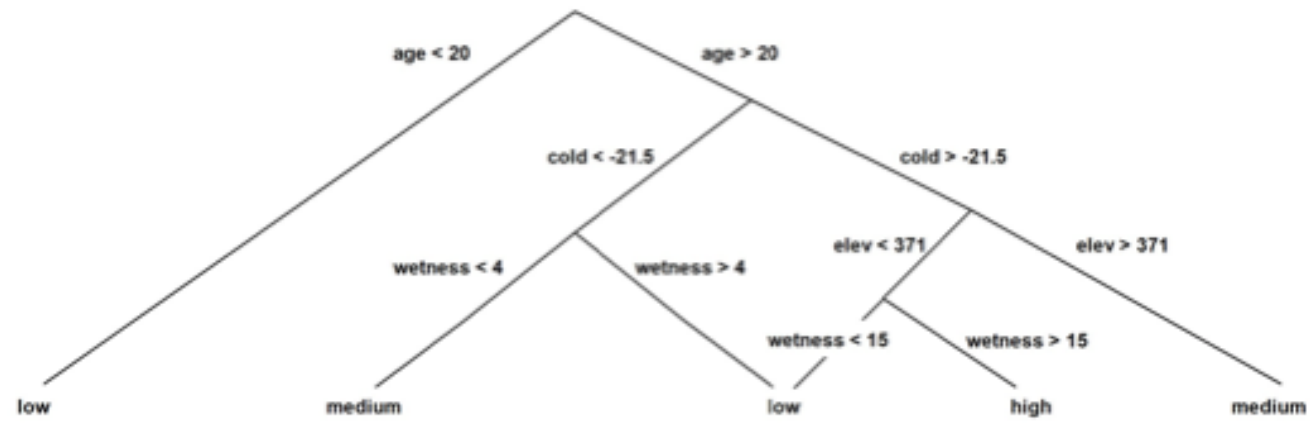

Fig. 3. A classification tree depicting the relationship between the relative abundance of the redbacked salamander and a set of environmental variables. Relative abundance is classed as low, medium or high each terminal node. 

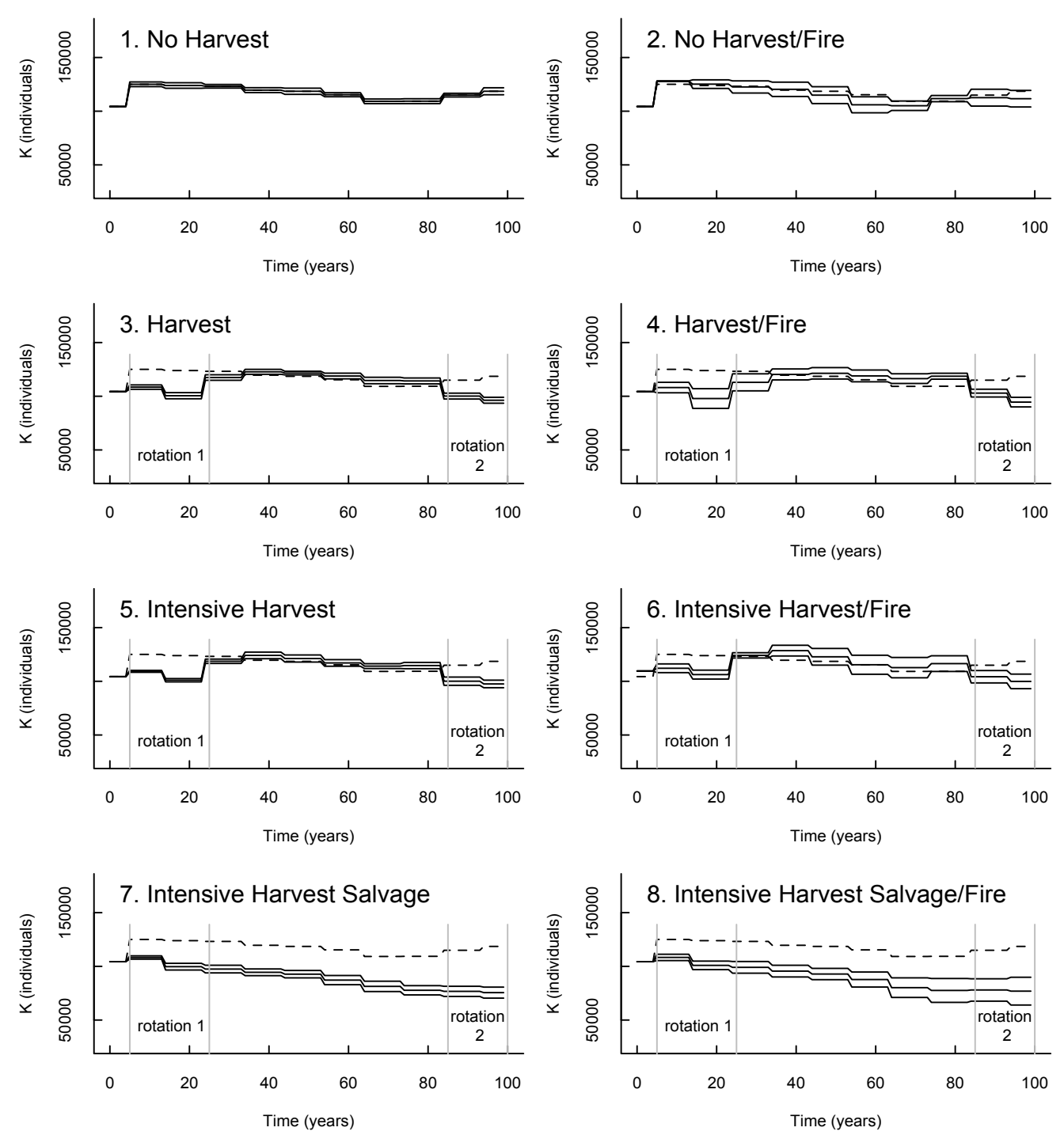

Fig. 4. The carrying capacity (K) for the red-backed salamander model for each management scenario. $\mathrm{K}$ is summed over all patches in the study area. On each graph, the middle line shows mean $\mathrm{K}$, while the upper and lower lines show one standard deviation from mean $\mathrm{K}$. The mean result from the No Harvest scenario is shown as a dashed line over the other plots. Vertical grey lines show where the two harvest rotations occur. 

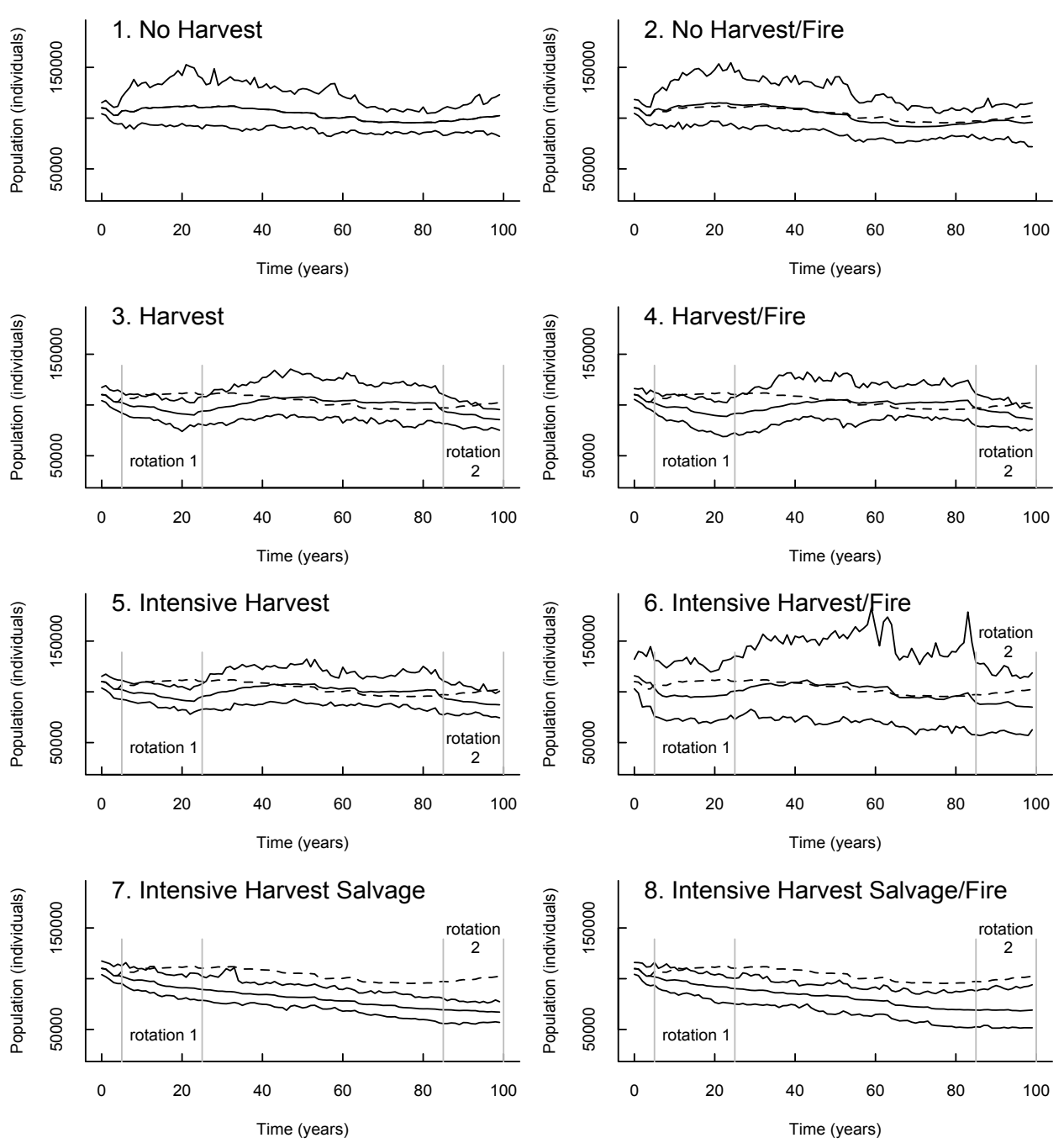

Fig. 5. Population trajectories for the red-backed salamander population model for each scenario. The middle line shows the mean population size, while the upper and lower lines show the maximum and minimum populations. The mean result from the No Harvest scenario is shown as a dashed line over the other plots. Vertical grey lines show where the two harvest rotations occur. 


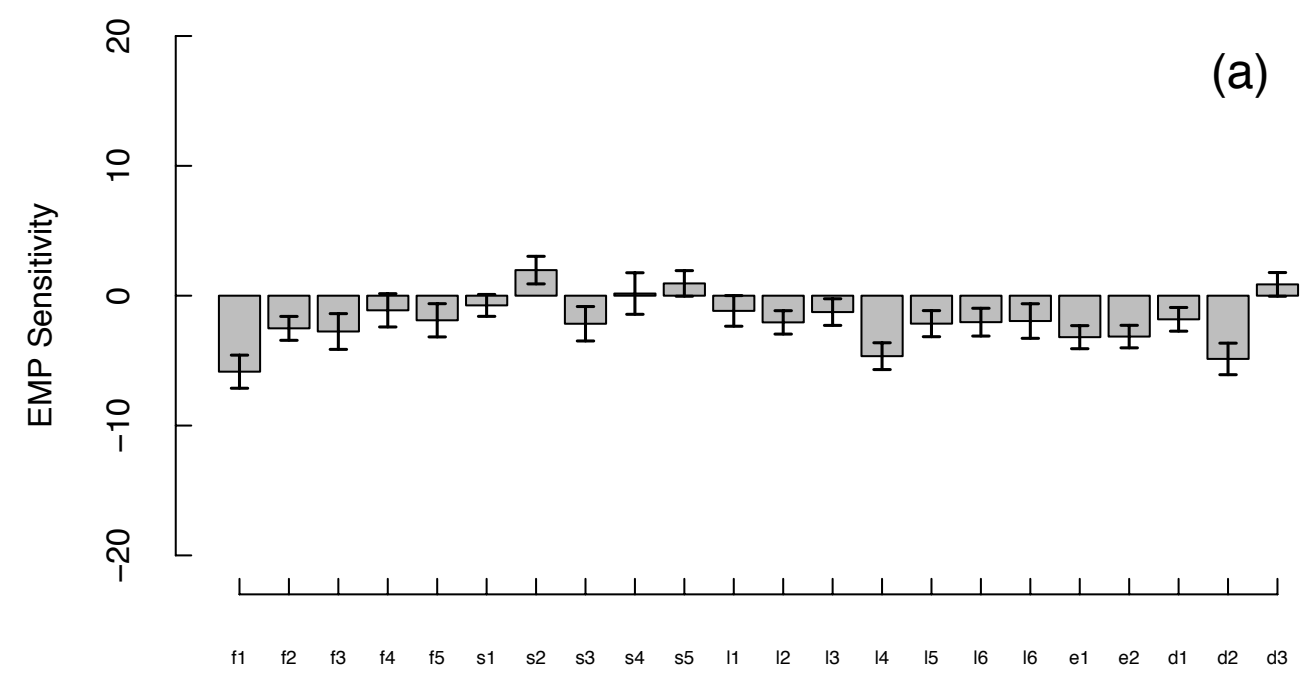

LANDIS Model Parameters

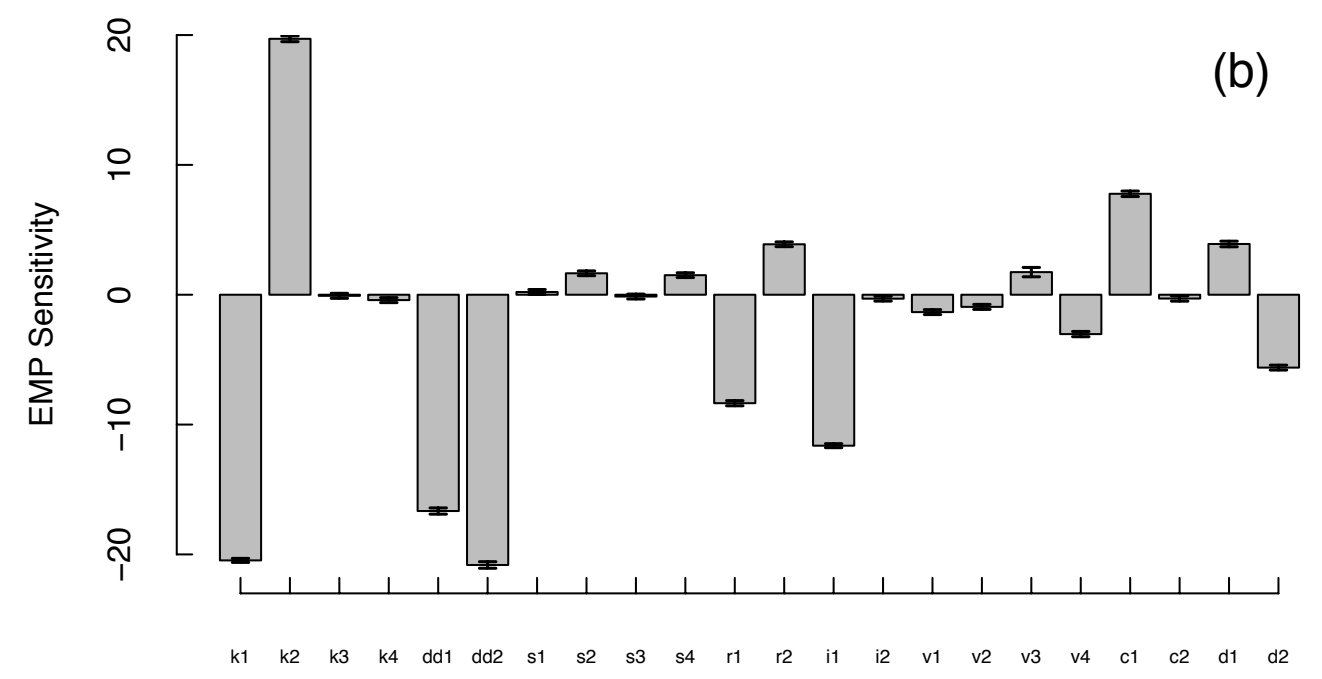

Metapop Model Parameters

Fig. 6. Sensitivity analysis results. The sensitivities of the LANDIS (a) and RAMAS GIS/

Metapop (b) models are shown. The model parameters are represented by alphanumeric codes.

The LANDIS model parameter categories are: $f$ - fire, $s$ - seed dispersal, $l$ - life history, $e-$ establishment probabilities and $d$-seeding distance. The Metapop/GIS model parameter categories are: $k$ - carrying capacity, $d d$ - density dependence, $s$-stochasticity, $r$ - maximum growth rate, $i$-initial abundance, $c$ - correlation, $d$ - dispersal, and $v-$ vital rates. See Appendix Table A2 for a detailed description of each of the model parameters. 


\section{Appendix}

\section{A1. Further details on the sensitivity analysis}

The fact that RAMAS Landscape can accommodate a maximum of 500 separate populations over the course of the simulation, places limits on modelling a species with a small home range such as the red-backed salamander model over large areas. To overcome this we amalgamated small populations by increasing the neighbourhood distance parameter in RAMAS GIS. To reduce the number of patches below 500 we also had to exclude isolated patches with an area less than 14 hectares. Patches of this size can have a maximum carrying capacity of 42 individuals and their exclusion reduced the total population by $1.4 \%$.

\section{A2. Further details on modelling fire disturbances}

To simulate fire, two key aspects of fire behaviour must be estimated: fire return time (mean) and fire size distribution (mean, upper and lower limits). In the boreal forest of Ontario, the natural fire cycle is thought to be 80 to 200 years, though modern fire suppression efforts may have increased the cycle to between 400 and 2000 years (Rowe and Scotter 1973). Average fire return times were estimated to be 110 years for jack pine dominated forests and 325 years for mixed species forests in the study region (M. Flannigan and T. Lynham, pers. comm.). A fire size distribution for the region was developed on the basis of fire history data collected between 1921 and 1999 for the study region (M. Flannigan, unpublished data). The data closely fitted an exponential distribution, matching the assumption of the LANDIS module (Akçakaya et al. 2003). The observed distribution of fire sizes results from a mixture of modern fire suppression methods in the late 1900s and less efficient fire suppression strategies in the early 1900s. The mean fire size was estimated to be approximately 2000 ha, with a lower and upper limit of 200 ha and 8000 ha respectively. A second fire scenario was modelled assuming that continued fire suppression will result in an increase to average fire return times and the long-run fire size distribution. The mean fire return interval for the second fire scenario was set to 320 years for jack pine and 700 years for mixed species. The fire size distribution increased in the second fire scenario so that the mean size was 8000 ha, the lower limit 6000 ha and the upper limit 10000 
ha. This scenario was developed to represent a proposed upper bound on the future fire size distribution.

Each of the for silvicultural scenarios modelled were subject to the two alternative fire regimes, one designed to describe recent historical fire size and frequency characteristics, and one designed to reflect potential changes in fire size and frequency that may result from continued fire suppression. A separate LANDIS model was developed for each of the eight combinations of harvesting and fire management and used to predict the future forest species composition and age-class distribution under each scenario. These eight scenarios are summarised in Table A1 below.

\section{Table A1. Details of the eight forest management scenarios}

Details of the eight forest management scenarios implemented, including forest composition, fire and harvesting regimes. Forest composition and structure changed according to successional processes driven by tree species and life history traits. Harvesting scenarios were developed to approximate specifications in the Natural Disturbance Emulation guidelines. For more information see the Ontario Forest Resource Inventory Database Users Manual (OMNR 2001). 


\section{Scenario number, Fire Regime \\ Harvesting Regime \\ name and \\ description}

\begin{tabular}{lll}
\hline 1. No Harvest & Fire size and return time & No timber harvesting \\
No timber harvesting & $\begin{array}{l}\text { parameters set to match current } \\
\text { and a natural fire }\end{array}$ & \\
estimates. &
\end{tabular}

regime.

\begin{tabular}{ll}
\hline 2. No Harvest/Fire & Fire return times were set to \\
No timber harvesting & 320 years for jack pine \\
with fire & dominated forest, and 700 \\
suppression. & years for mixed forests. The \\
& fire size distribution was set to \\
& a mean of 8000 ha, with upper \\
& and lower limits of 10000 and \\
& 6000 ha respectively.
\end{tabular}

3. Harvest $\quad$ Same as scenario 1

The total area harvested is approximately

Natural disturbance

emulation harvesting

guidelines with

natural fire regime.

18000 ha in each of two rotations. The first

rotation starts at the beginning of the

simulation. All 18000 ha are harvested within

the first 20 years of the simulation. Harvesting

in the second rotation is completed in the $90^{\text {th }}$

and $100^{\text {th }}$ year of the simulation. Both harvest

and burnt areas need at least 20 years to

become suitable habitat again.

4. Harvest/Fire $\quad$ Same as scenario 2 Same as scenario 3
Natural disturbance
emulation harvesting
guidelines with fire
suppression.


5. Intensive Harvest Same as scenario 1

Intensive harvesting

with a natural fire

regime.
Similar to scenario 3 , but involves an increase in the intensity of silviculture. The timing of harvesting events is the same as in scenario 3 . All areas nominated for harvesting are clearcut and replanted to jack pine. Harvested areas still become suitable habitat after 20 years. Edge effects at the clearcut-forest interface following logging are included.

\begin{tabular}{|c|c|c|}
\hline $\begin{array}{l}\text { 6. Intensive } \\
\text { Harvest/Fire } \\
\text { Intensive harvesting } \\
\text { with fire } \\
\text { suppression. }\end{array}$ & Same as scenario 2 & Same as scenario 5 \\
\hline $\begin{array}{l}\text { 7. Intensive Harvest } \\
\text { Salvage } \\
\text { Intensive harvesting } \\
\text { with natural fire } \\
\text { regime and salvage } \\
\text { logging in burnt } \\
\text { loggable areas. }\end{array}$ & Same as scenario 1 & $\begin{array}{l}\text { Similar to scenario 5, though the total } \\
\text { harvested area effectively increases, as areas } \\
\text { burnt by wild fire are then salvage logged and } \\
\text { planted with jack pine. Both harvested and } \\
\text { burnt areas are excluded from becoming } \\
\text { suitable habitat for the rest of the simulation. } \\
\text { Edge effects at the clearcut-forest interface } \\
\text { following logging are included. }\end{array}$ \\
\hline $\begin{array}{l}\text { 8. Intensive Harvest } \\
\text { Salvage/Fire }\end{array}$ & Same as scenario 2 & Same as scenario 7 \\
\hline Intensive harvesting & & \\
\hline with fire suppression & & \\
\hline and salvage logging & & \\
\hline $\begin{array}{l}\text { in burnt forest under } \\
\text { an altered fire }\end{array}$ & & \\
\hline regime. & & \\
\hline
\end{tabular}


Table A2. A description of each parameter change in the DLMP model sensitivity analysis.

The table shows the parameter settings corresponding to the alphanumeric codes shown in Figure 6. The sensitivity of the LANDIS model parameters were determined by running RAMAS Landscape for 120 minutes with each parameter setting. The sensitivity of the metapopulation model was conducted using 500 repetitions of the metapopulation model on a single landscape realization, to avoid the potentially confounding effects of landscape stochasticity. 


\begin{tabular}{|c|c|}
\hline Alphanumeric code & Description \\
\hline \multicolumn{2}{|l|}{ LANDIS Parameters } \\
\hline$f 1$ & Fire suppression (identical to the No Harvest/Fire scenario) \\
\hline$f 2$ & $\begin{array}{l}\text { LANDIS, land types, changed fire curve (set all fire class to 1, except in last } \\
\text { entry for number of years since the last disturbance) }\end{array}$ \\
\hline$f 3$ & $\begin{array}{l}\text { LANDIS, land types, changed fire curve (set all fire class to } 5 \text {, except in first } \\
\text { entry for number of years since the last disturbance) }\end{array}$ \\
\hline f4 & $\begin{array}{l}\text { LANDIS, land types, changed fire curve (set all fire class to 1, except in last } \\
\text { entry for number of years since the last disturbance) as well as fire suppression } \\
\text { (identical to the No Harvest/Fire scenario) }\end{array}$ \\
\hline$f 5$ & $\begin{array}{l}\text { LANDIS, land types, changed fire curve (set all fire class to } 5 \text {, except in first } \\
\text { entry for number of years since the last disturbance) as well as fire suppression } \\
\text { (identical to the No Harvest/Fire scenario) }\end{array}$ \\
\hline$s 1$ & LANDIS, seed dispersal method set to effective distance \\
\hline$s 2$ & LANDIS, general, seed dispersal set to neighbours \\
\hline$s 3$ & LANDIS, general, seed dispersal method set to max distance \\
\hline$s 4$ & LANDIS, general, seed dispersal method set to very slow \\
\hline s5 & LANDIS, general, seed dispersal method set to uniform \\
\hline$l 1$ & $\begin{array}{l}\text { LANDIS, life history, fire tolerance incremented by } 1 \text { (parameter is an integer } \\
\text { between } 1 \text { and 5) }\end{array}$ \\
\hline 12 & $\begin{array}{l}\text { LANDIS, life history, fire tolerance incremented by }-1 \text { (parameter is an integer } \\
\text { between } 1 \text { and 5) }\end{array}$ \\
\hline 13 & LANDIS, life history, longevity increased by $20 \%$ \\
\hline 14 & LANDIS, life history, longevity decreased by $20 \%$ \\
\hline 15 & LANDIS, life history, maturity increased by $20 \%$ \\
\hline 16 & LANDIS, life history, maturity decreased by $20 \%$ \\
\hline 16 & LANDIS, life history, shade tolerance multiply by 1.2 \\
\hline el & LANDIS, land types, probability increase by $20 \%$ for all species \\
\hline$e 2$ & LANDIS, land types, probability decreased by $20 \%$ for all species \\
\hline$d 1$ & LANDIS, life history, effective and max seeding distance increase by $50 \%$ \\
\hline$d 2$ & LANDIS, life history, effective and max seeding distance decrease by $50 \%$ \\
\hline$d 3$ & LANDIS, life history, check unlimited effective and max seeding distance \\
\hline
\end{tabular}




\begin{tabular}{ll}
\hline Alphanumeric code & \multicolumn{1}{c}{ Description } \\
\hline$R A M A S$ GIS and Metapop Parameters & Decrease K by $20 \%$ in Link to metapopulation \\
$k 1$ & Increase K by $20 \%$ in Link to metapopulation \\
$k 3$ & Standard deviation change from 0.1 to 0 in default population (density dependence) \\
$k 4$ & Standard deviation change from 0.1 to 0.2 in default population (density dependence) \\
$d d 1$ & Metapop model changed so that density dependence affects survival rates \\
$d d 2$ & Metapop model changed so that density dependence affects all vital rates \\
$s 1$ & Metapop model stochasticity (un-check, use demographic stochasticity) \\
$s 2$ & Metapop model stochasticity (lognormal, F,S and K uncorrelated) \\
$s 3$ & Metapop model stochasticity (normal, all correlated) \\
$s 4$ & Metapop model stochasticity (normal, F,S and K uncorrelated) \\
$r 1$ & Landscape model, link to metapop, general, Maximum growth (Rmax 1.1$)$ \\
$r 2$ & Landscape model, link to metapop, general, Maximum growth (Rmax 1.3 ) \\
$i 1$ & Landscape model, link to metapop, general, initial abundance, increased by $40 \%$ \\
$i 2$ & Landscape model, link to metapop, general, initial abundance, decreased by $40 \%$ \\
$v 1$ & Metapop model, stage matrix, decrease each value by $20 \%$ \\
$v 2$ & Metapop model, stage matrix, increase each value by $20 \%$ \\
$v 3$ & Metapop model, standard deviation matrix, decrease each value by $20 \%$ \\
$v 4$ & Metapop model, stage matrix, increase each value by $20 \%$ \\
$c 1$ & Landscape, RAMAS model, correlation, set a to 0 \\
$c 2$ & Landscape, RAMAS model, correlation, set a to a $=0.5 \mathrm{~b}=2 \mathrm{c}=1 \mathrm{~d}=1.1$ \\
$d 1$ & Landscape, RAMAS model, dispersal, set a to 0 \\
\hline
\end{tabular}

\section{References}

Akçakaya, H.R., Mladenoff, D.L., and He, H.S., 2003. RAMAS Landscape: integrating metapopulation viability with LANDIS forest dynamics model. User manual for version 1.0. Applied Biomathematics. Setauket, New York.

OMNR (1997) Ontario forest resource inventory database users manual. Ontario Ministry of Natural Resources, Queens Printer for Ontario, Toronto.

Rowe, J.S. and Scotter, G.W. 1973. Fire in the boreal forest. Quaternary Res. 3: 444-464. 